\title{
Extreme hemodynamic fluctuations: Importance of understanding the principles of syringe pump function
}

\author{
Sir, \\ Infusion devices remain high-risk devices capable of \\ delivering drugs unpredictably leading to mortality and \\ morbidity. The problem of performance, degradation, \\ and quality was the cause for $20 \%$ of reported incidences \\ relating to the infusion pump in UK between 1990
}


and 2000.[1] Thus, it is important for the clinician to be familiar with the features and function of the infusion device they are using.

A 55-year-old lady with middle cerebral artery aneurysm underwent microsurgical clipping of the aneurysm under general anesthesia uneventfully. After clipping, with the target of raising systolic blood pressure (SBP) to $160 \mathrm{~mm} \mathrm{Hg}$, noradrenalin infusion was started at $1.6 \mu \mathrm{g} / \mathrm{min}$. The solution was prepared in a $50 \mathrm{ml}$ syringe with $8 \mathrm{mg}$ of noradrenaline bitartrate diluted in $40 \mathrm{~mL}$ normal saline and infused at $2 \mathrm{~mL} / \mathrm{h}$. The solution was infused using Orchestra ${ }^{\circledR}$ DPS + (Fresenius Kabi) infusion pump. (Ref 082594/21126459) La Grand Chamin-38590 Brezins- France. Initially, there was a surge in SBP up to $240 \mathrm{~mm} \mathrm{Hg}$. No intervention was done as the surge was expected to settle down. However, after the blood pressure decreased to $110 \mathrm{~mm} \mathrm{Hg}$, there was another surge in SBP up to $200 \mathrm{~mm} \mathrm{Hg}$ after approximately $5 \mathrm{~min}$. This was followed by 4 similar cyclical surges at $10 \mathrm{~min}$ intervals [Figure 1]. We changed the syringe but again the fluctuations in blood pressure persisted.

Pulsatile flow of drug at low dose rates in syringe pump was then thought to be the cause and to smoothen the fluctuations, the drug in the syringe solution was double diluted (i.e. $4 \mathrm{mg}$ in $40 \mathrm{~mL}$ ) and the dose rate was also doubled $(4 \mathrm{~mL} / \mathrm{h})$. Following this intervention, the surges flattened out considerably, and the SBP fluctuated between 170 and $150 \mathrm{~mm} \mathrm{Hg}$ thereafter [Figure 1].

The Orchestra ${ }^{\circledR}$ DPS + pump uses stepper motors with the lead screw, and the flow rate accuracy of the motor is documented to be $\pm 1 \%$ on drive mechanism and $\pm 2 \%$ on syringes. ${ }^{[2]}$ However, at low flow rates, the flow may be discontinuous and pulsatile. Stepper

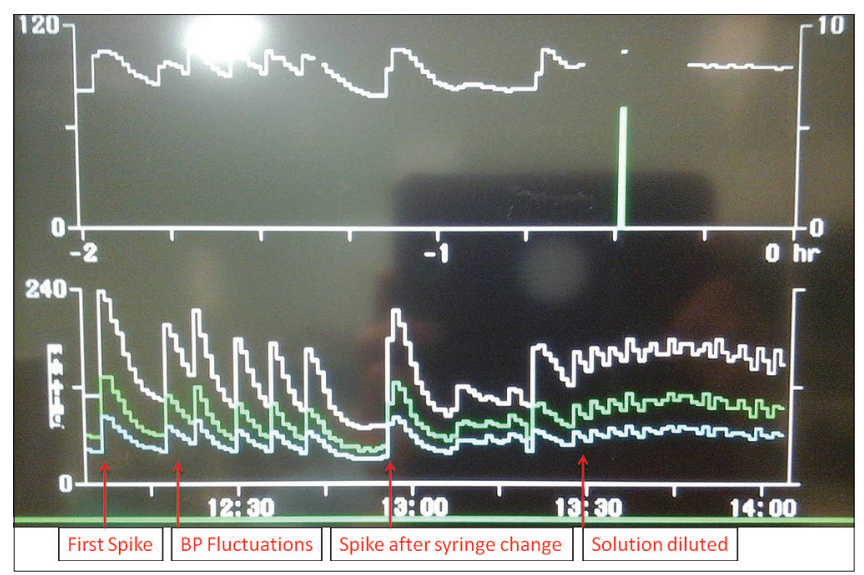

Figure I: Snapshot showing graphical representation of fluctuation in invasive blood pressure motors are known to produce flow in a series of discrete fixed volume pulses. The volume and rate of pulses at fixed flow rates depend on the number of steps per revolution of the lead screw. If the time duration between the pulses is relatively large compared to the half-life of the drug, the result may be wide variation in effect of the drug. ${ }^{[3]}$ Another reason may be stiction (i.e., the friction which tends to prevent stationary surfaces from being set in motion) between syringe plunger and barrel. ${ }^{[4]}$ A similar problem was investigated by Capes et al. and they found Terumo syringes to be significantly associated with the noncontinuous flow. ${ }^{[5]}$

In our case, the syringe change did not affect the fluctuations while increasing the flow rates with the same syringe caused smoothening of fluctuations. Thus, it appears that the motor mechanism to be at fault at low flow rates. This effect though occasionally observed is of serious concern and the technique described here may be easily employed to mitigate the problem.

Chakrabarti Dhritiman, Byrappa Vinay ${ }^{1}$

Department of Anaesthesia, Sakra World Hospital, ${ }^{1}$ Department of Neuroanaesthesia, National Institute of Mental Health and Neurosciences, Bengaluru, Karnataka, India

Correspondence:
Dr. Byrappa Vinay,
Department of Anaesthesia,
Sakra World Hospital,
Bengaluru - 560 103, Karnataka, India.
E-mail: vini.leo24@gmail.com

\section{References}

1. Diba A. Infusion equipment and intravenous anaesthesia. In: Davey JA, Diba A, editors. Ward's Anaesthetic Equipment. $5^{\text {th }}$ ed. Philadelphia, USA: Elsevier Saunders; 2005. p. 409-26.

2. Orchestra ${ }^{\circledR}$ DPS+Data Sheet (Fresenius Kabi, Bad Homburg, Germany). [Last accessed on 2014 Oct 01].

3. Available from: http://www.hospira.com/Images/P11_3241_Infusion_ Pump_Therapy_Pocket_Guide_FINAL_32-90336_1.pdf. [Last accessed on 2014 Jul 17].

4. Ferrari R, Beech DR. Infusion pumps: Guidelines and pitfalls. Aust Prescriber 1995;18:49-51.

5. Capes DF, Dunster KR, Sunderland VB, McMillan D, Colditz PB, McDonald C. Fluctuations in syringe-pump infusions: Association with blood pressure variations in infants. Am J Health Syst Pharm 1995;52:1646-53.

\section{Access this article online}

\begin{tabular}{|l|l|}
\hline \multicolumn{2}{|c|}{ Access this article online } \\
\hline Quick Response Code: & Website: \\
\hline & www.jiccm.org \\
\cline { 2 - 2 } & DOI: 10.4103/0972-5229.154589 \\
\hline
\end{tabular}

